\title{
Fibrin glue provides stronger mesh fixation than tacks: An in-vitro study
}

\author{
David Hamilton, Jeremy Tan and Harsha Chandraratna* \\ St John of God Medical Centre Murdoch, Australia
}

\begin{abstract}
Introduction: With inguinal hernia recurrence rates following surgical repair having been reduced in the mesh era, avoiding chronic pain post-operatively has become the new "holy grail" for hernia surgeons. Tacks used for fixating the mesh in laparoscopic inguinal hernia repair have been proven as a cause of chronic pain and thus the use of fibrin glue has been suggested as an alternative. Intuitively, it was felt that glue would not provide as strong a fixation as tacks and thus we set out to test this hypothesis.
\end{abstract}

Methods: A standard size of mesh was fixated to pieces of steak using either absorbable tacks or fibrin glue. The amount of force required to pull the mesh off the steak was then measured.

Results: The average force required to dislodge the mesh from the steaks was $6.40 \pm 1.50 \mathrm{~N}$ for the tacks and $15.34 \pm 3.93 \mathrm{~N}$ for the fibrin glue. This difference was statistically significant with a p-value of 0.03 .

Conclusion: Fibrin glue provides a stronger fixation of mesh to muscle, when compared to tacks in an in-vitro situation.

\section{Introduction}

There has been a paradigm shift in the thinking and attitudes of surgeons towards inguinal hernia. Twenty years ago, the emphasis on hernia repair focused on minimising hernia recurrence. This was probably a reflection of the attitudes of surgeons in managing recurrent hernias in the pre-mesh era, and the higher rates of recurrence in nonmesh (tissue) hernia repair. Managing a recurrent hernia without mesh is technically very difficult, and most modern (younger) surgeons have minimal experience with these types of techniques.

Preventing hernia recurrence is still a major consideration in inguinal hernia repair but the focus now has moved to the prevention or avoidance of chronic severe groin pain after hernia repair.

Chronic severe groin pain can be disabling and have significant impact in the ability of the individual to work, maintain their income and also has similar significant impact to an individual's personal life. It is often long-lasting and may need multiple interventions for its reduction or resolution. It may also require ongoing management from a chronic pain perspective. All of which carry a financial and personal cost.

One of the major advantages of laparoscopic pre-peritoneal hernia repair is the ability to place the mesh away from the ilioinguinal and iliohypogastric nerves. It has been shown to reduce the incidence of groin pain [1]. These techniques may have slightly higher rates of recurrence but the risks of this is significantly counterbalanced by a reduction in groin pain [2]. We see the main advantage of laparoscopic pre-peritoneal hernia repair is thus the reduction of chronic groin pain.

Even in laparoscopic pre-peritoneal hernia repairs, chronic groin pain does occur. The triangle of pain is well described, and tacks placed lateral to the spermatic cord or round ligament, below the inguinal ligament are at high risk of entrapping a nerve fibre and causing chronic pain. All laparoscopic inguinal hernia surgeons would thus be well advised to avoid placing tacks in this area.

A review of laparoscopic inguinal hernia surgery showed that the incidence of chronic groin pain was higher with the use of absorbable tacks [3]. However, on further review it became apparent that this was because when surgeons used dissolving tacks they tended to use more of them. So, when the data was re-examined it became apparent that the incidence of chronic groin pain was related to the number of tacks used regardless of absorbable or permanent. So, the logical step forward was to use less or no tacks [3,4].

Meshes have been developed that self-secure themselves - Progrip (Medtronic Inc) which acts like Velcro has an intrinsic ability to grip the tissue and secure itself. The data on chronic groin pain incidence with this technique is still yet to evolve, and this type of mesh can be difficult to work with in a confined laparoscopic environment.

Parietex DP2 (Medtronic Inc) has a wraparound feature to encircle the spermatic cord / round ligament and secure itself and may offer a reduction in groin pain. But the data here is also not yet available.

Surgeons using these two meshes may still require further fixation with tacks.

${ }^{\star}$ Correspondence to: Harsha Chandraratna, General and Obesity Surgeon, Suite 27 St John of God Medical Centre Murdoch, 100 Murdoch Drive, Murdoch WA 6150, Surgeons House, 162 Cambridge St, West Leederville WA 6007,117 Anstruther Rd, Mandurah, Australia, Tel: (08) 9332 0066, 0401809255; Fax: (08) 9463 6202; E-mail: drchandra@westnet.com.au

Received: October 05, 2018; Accepted: October 16, 2018; Published: October 22, 2018 
The next logical step to get good mesh fixation to prevent early migration of mesh and recurrent hernia would be to use a glue to fixate the mesh. Using glue in the triangles of pain and doom (medial to the spermatic cord / round ligament) is safe and provides fixation where tacks cannot. Also, securing the mesh inferiorly seems to make more sense as this seems to be where recurrences occur, with the peritoneum migrating up from underneath the inferior border of the mesh.

This may represent a system that may prevent or reduce hernia recurrence and also minimize chronic severe groin pain $[5,6]$.

We set out to test in an in-vitro model how strong is the glue in adhering the mesh to muscle layer when compared to tacks.

\section{Methods}

We created a system to measure the force required to dislodge a mesh (C-Qur Fx, Atrium-Maquet, Inc) that had been fixated into muscle. To compare the difference between fibrin glue (Tisseel, Baxter Inc.) and tacks (Absorbatack, Medtronic Inc).

Using a pulley system, a suture was placed through the centre of the mesh and the mesh was then fixated to the muscle. Once fixated it was then attached to a pulley mechanism where we could add weights sequentially and to measure amount of force needed to dislodge the fixated mesh from the muscle. The muscle (beef - fillet steak) was secured to a wooden board using roofing nails and washers (Figures $1 \mathrm{a}$ and $1 \mathrm{~b})$.

The mesh was cut into standard sized pieces of $7 \mathrm{~cm} \times 7 \mathrm{~cm}$ and fixated by either;

a) 4 tacks $1 \mathrm{~cm}$ from each corner

or

b) Tisseel Glue $5 \mathrm{mls}$. The glue was allowed to warm to room temperature and the meat was warmed to 37 degrees Celsius. The glue was allowed to set for 5 minutes. (The manufacturer advises 3 minutes). The glue was applied to the under surface of the mesh and then the glue was allowed to set without any pressure on the mesh.

Weights were then added sequentially to see how much force was required to dislodge the mesh.

\section{Results}

The average force required to dislodge the mesh from the steaks was $6.40 \pm 1.50 \mathrm{~N}$ for the tacks and $15.34 \pm 3.93 \mathrm{~N}$ for the fibrin glue. This difference was statistically significant with a p-value of 0.03 (Table 1) and (Figure 2).

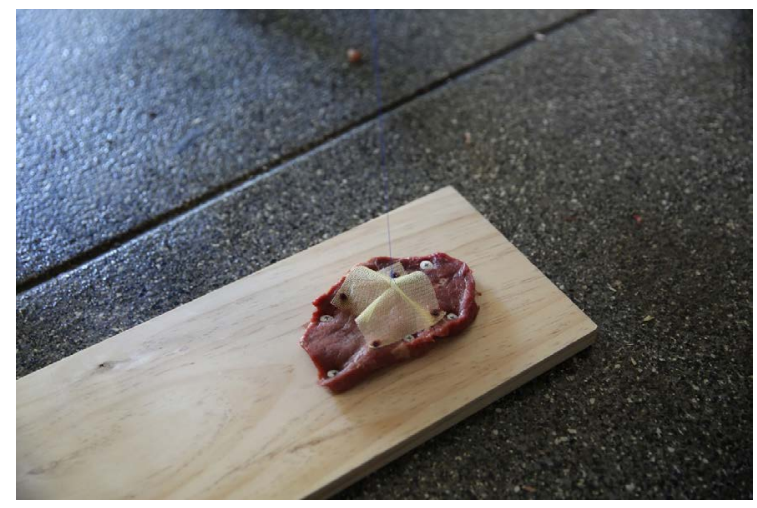

Figure 1a. Close-up of tack fixation

The Student's t-test was used to look for a difference between the two groups

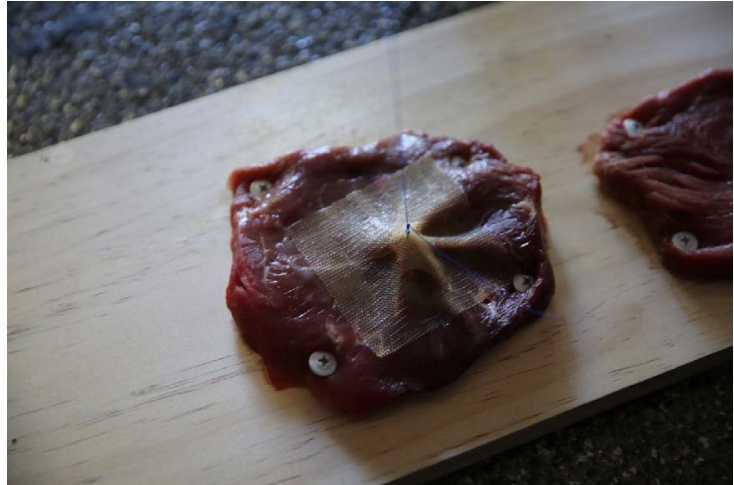

Figure 1b. Close-up of glue fixation

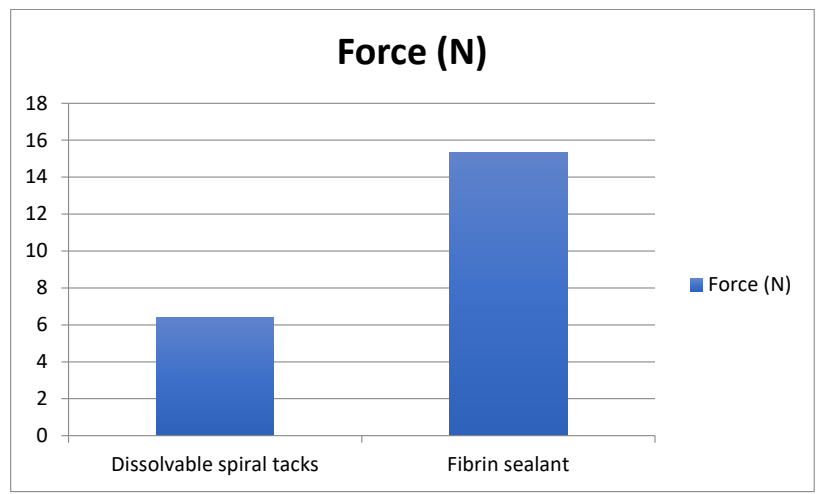

Figure 2. Average force required to dislodge mesh

Table 1. Results (kg)

\begin{tabular}{|c|c|c|}
\hline Method of mesh fixation & Absorbatack & Tisseel Fibrin sealant \\
\hline 1 & 0.82 & 1.49 \\
\hline 2 & 0.62 & 1.21 \\
\hline 3 & 0.52 & 2 \\
\hline Average & 0.653 & 1.567 \\
\hline Average per cm squared & 0.0133 & 0.0319 \\
\hline
\end{tabular}

\section{Discussion}

Tisseel Glue provides a stronger fixation than absorbable tacks.

What did become apparent in the preparation for this study was also very useful. The tacks were more effective if firm pressure is applied to the tack, either as forward pressure on the applicator or counter pressure on the tissue being applied to. Increased pressure will facilitate deeper penetration of the tack, which may provide better fixation but may cause more pain or discomfort. This is especially true in thinner patients where the tacks can irritate the skin from underneath. We also found that spraying the glue through the mesh did not work, with the glue preferring to activate and set on top of the mesh and thus providing very little fixation at the mesh-muscle interface. It was better to lift the mesh and place the glue underneath the mesh and this allowed much better bonding of the mesh to the muscle.

Clarke et al. [7] tested a combination of glue and tacks in a laparoscopic ventral hernia model in pigs. They found no difference in tensile strength of mesh fixation between a combination of glue and tacks when the pigs were sacrificed at 30 days.

Likewise, Erikssen et al. [8] performed a randomized controlled trial comparing Tisseel and titanium tacks in a laparoscopic ventral hernia 
model in pigs. They found no significant difference in the strength of ingrowth between the two groups at 30 days when the animals were sacrificed.

As far as we know, this is the first study which tests the immediate tensile strength of mesh fixation using tacks versus glue in an in-vitro model.

Interestingly, $4 \mathrm{~mL}$ of Tisseel Duo can be purchased for USD \$270, whereas one Absorbatack device is USD \$450. Ten $\mathrm{mL}$ Tisseel Duo is USD \$627.

Limitations of the study include the fact that it is an in-vitro study and the number of trials for each modality was small. Also, tacks were placed at the four corners of the mesh, which is not the practice of most laparoscopic inguinal hernia repair surgeons. Tensile strength was also measured as force used to pull the mesh away from the muscle and shearing forces were not tested. The forces needed to dislodge a mesh in-vivo are unknown.

Nevertheless, this is the first study of any kind to show any advantage of glue fixation over mesh.

\section{Conclusion}

The fixation provided by glue is stronger than tacks in the immediate post-procedure period, but both are currently accepted methods for fixating mesh. Further study in an in-vivo model should be contemplated.

\section{Relevant disclosures}

Dr Chandraratna has been provided with educational support from Baxter, Atrium Maquet, and Medtronic previously.
We would like to thank Medtronic, Baxter Health Care and Atrium Maquet for the donation of equipment to facilitate this study.

We would like acknowledge Atrium-Maquet, Baxter and Medtronic for the donation of the equipment used in this study

\section{References}

1. Lau H (2005) Fibrin sealant versus mechanical stapling for mesh fixation during endoscopic extraperitoneal inguinal hernioplasty: a randomized prospective trial. Ann Surg 242: 670-675. [Crossref]

2. Eklund AS, Montgomery AK, Rasmussen IC, Sandbue RP, Bergkvist LA, et al. (2009) Low recurrence rate after laparoscopic (TEP) and open (Lichtenstein) inguinal hernia repair: a randomized, multicenter trial with 5-year follow-up. Ann Surg 249: 33-38. [Crossref]

3. Kaul A, Hutfless S, Le H, Hamed SA, Tymitz K, et al. (2012) Staple versus fibrin glue fixation in laparoscopic total extraperitoneal repair of inguinal hernia: a systematic review and meta-analysis. Surg Endosc 26: 1269-1278. [Crossref]

4. Fenger AQ, Helvind NM, Pommergaard HC, Burcharth J, Rosenberg J, et al. (2016) Fibrin sealant for mesh fixation in laparoscopic groin hernia repair does not increase long-term recurrence. Surg Endosc 30: 986-992. [Crossref]

5. de Goede B, Klitsie PJ, van Kempen BJ, Timmermans L, Jeekel J, et al. (2013) Metaanalysis of glue versus sutured mesh fixation for Lichtenstein inguinal hernia repair. $\mathrm{Br}$ J Surg 100: 735-742. [Crossref]

6. Fortelny RH, Petter-Puchner AH, Glaser KS, Redl H (2012) Use of fibrin sealant (Tisseel/Tissucol) in hernia repair: a systematic review. Surg Endosc 26: 1803-1812. [Crossref]

7. Clarke T, Katkhouda N, Mason RJ, Cheng BC, Algra J, et al. (2011) Fibrin glue for intraperitoneal laparoscopic mesh fixation: a comparative study in a swine model. Surg Endosc 25: 737-748. [Crossref]

8. Eriksen JR, Bech JI, Linnemann D, Rosenberg J (2008) Laparoscopic intraperitoneal mesh fixation with fibrin sealant (Tisseel) vs. titanium tacks: a randomised controlled experimental study in pigs. Hernia 12: 483-491. [Crossref]

Copyright: (C2018 Hamilton D. This is an open-access article distributed under the terms of the Creative Commons Attribution License, which permits unrestricted use, distribution, and reproduction in any medium, provided the original author and source are credited. 